\title{
THE APRIL MEETING AT STANFORD UNIVERSITY
}

The three hundred twenty-first meeting of the Society was held at Stanford University on Saturday, April 6, 1935. The meeting was called to order at 10:30 A.M., and was presided over at different times by Professors Blichfeldt and Bateman. There was a morning and an afternoon session.

Some forty people were present, including the following twenty-four members of the Society:

H. M. Bacon, Harry Bateman, B. A. Bernstein, H. F. Blichfeldt, F. A. Butter, C. E. Corbin, G. C. Evans, E. C. Goldsworthy, O. G. Harrold, E. R. Hedrick, R. D. James, D. N. Lehmer, S. H. Levy, C. F. Luther, J. C. C. McKinsey, W. A. Manning, A. D. Michal, C. B. Morrey, S. L. Parker, T. M. Putnam, Pauline Sperry, J. V. Uspensky, A. R. Williams, B. C. Wong.

Luncheon for members and their guests was served at the Stanford Union.

The titles of papers read at the meeting follow. Those whose abstract numbers are followed by the letter $t$ were read by title. Mr. P. O. Bell and Miss Manning were introduced by Professor Manning; Mr. Webb was introduced by Professor Bell; Messrs. Elconin, Paxson, Highberg, and Taylor were introduced by Professor Michal; in the absence of Mr. Webb and Mr. Elconin their papers were read by Professor Michal.

1. Tetrahedra associated with canonical developments for the equation of a curved surface, by Mr. P. O. Bell. (Abstract No. 41-3-144.)

2. The problem of the shopper, by Professor Harry Bateman. (Abstract No. 41-3-145.)

3. Generation of an n-valued logic by one binary operation, by Mr. D. L. Webb. (Abstract No. 41-3-146.)

4. A theorem relating the differentials of Fréchet and Gateaux, by Mr. V. Elconin. (Abstract No. 41-3-161.)

5. A reduced set of postulates for Riemannian differential geometry in abstract vector spaces, by Professor A. D. Michal. (Abstract No. 41-3-148.)

6. Postulates for Boolean algebra involving the operation of complete disjunction, by Professor B. A. Bernstein. (Abstract No. 41-3-163.) 
7. On geometry of numbers, by Professor H. F. Blichfeldt. (Abstract No. 41-3-155.)

8. Sets of independent postulates for linear spaces and vector spaces, by Mr. I. E. Highberg and Mr. A. E. Taylor. (Abstract No. 41-3-159.)

9. The geometry of abstract euclidean spaces, by Mr. I. E. Highberg, Professor A. D. Michal, and Mr. A. E. Taylor. (Abstract No. 41-3-158.)

10. On simply transitive permutation groups with transitive Abelian subgroups of the same degree, by Miss Dorothy Manning. (Abstract No. 41-3-154.)

11. New results for the number $g(n)$ in Waring's problem (preliminary report), by Dr. R. D. James and Mr. H. S. Zuckerman. (Abstract No. 41-3-162.)

12. A simple proof of Tschebysheff's inequalities, by Professor J. V. Uspensky. (Abstract No. 41-3-156.)

13. A simplification in the theory of weak convergence, by Professors H. E. Bray and G. C. Evans. (Abstract No. 41-3165.)

14. Correspondences connected with a pencil of $n$-ics, by Professor A. R. Williams. (Abstract No. 41-3-164.)

15. A note on Taylor's theorem, by Professor A. F. Moursund. (Abstract No. 41-3-149-t.)

16. A new solution of the Gauss problem on $h\left(s^{2} d\right) / h(d)$, by Professor Gordon Pall. (Abstract No. 41-3-150-t.)

17. Configurations inscriptible in a plane cubic curve, by Dr. J. M. Feld. (Abstract No. 41-3-151-t.)

18. A detail in Kronecker's program, by Professor E. T. Bell. (Abstract No. 41-3-152-t.)

19. An abstract triplet metric space (preliminary report), by Mr. E. W. Paxson. (Abstract No. 41-3-153-t.)

20. Primitive functions on a finite set, by Mr. V. Elconin. (Abstract No. 41-3-147-t.)

21. A fallacy of the so-called osculatory interpolation formulas, by Professor C. H. Forsyth. (Abstract No. 41-3-157-t.)

22. A set of independent postulates for a metric space, by $\mathrm{Mr}$. A. E. Taylor. (Abstract No. 41-3-160-t.)

T. M. Putnam, Associate Secretary 